\title{
Concern-Focused Evaluation for Ambiguous and Conflicting Policies: An Approach From the Environmental Field
}

\author{
Laurent Mermet ${ }^{1}$, Raphaël Billé ${ }^{2}$, and Maya Leroy ${ }^{3}$
}

\begin{abstract}
Environment and sustainable development show how policies are becoming ever more complex and ambiguous. This trend calls for new evaluation approaches. They need to be more clearly focused on specific, explicit concerns. They must be driven by a strategic concept of use to overcome the vulnerability to manipulation of many integrative, essentially procedural, approaches to policy making and evaluation. This article presents a conceptual framework for such evaluations and a four-step approach: defining the focal concern; developing criteria and synthesizing observations on the extent to which the focal concern is met; identifying and assessing all policies contributing to this outcome; and complementing this with the evaluation of policies specifically aimed at meeting the focal concern. Examples are taken essentially from wetland-related policies in France and Senegal. The article discusses how this approach tackles some crucial issues in evaluation research and practice and advocates closer connections between evaluation and critical research on policies.
\end{abstract}

Keywords

environmental policy, integrated policy, strategic evaluation, wetland policy

Environmental policy is no longer a new or emerging field. For most issues - whether biodiversity conservation, water quality, waste management, or air pollution, and so on - public policies have been developing on large scale for more than 30 years. The evaluation of environmental policies, however, still remains a rather tentative domain (Crabbé \& Leroy, 2008; Knaap \& Kim, 1998;

Mickwitz, 2003). In their recent Handbook of Environmental Policy Evaluation, Crabbé and Leroy (2008) observe that there is some difficulty, due to "the specific complexities of this field," in applying to environmental policies the tested and honed generic methods of the policy evaluation field.

\footnotetext{
${ }^{1}$ AgroParisTech, UMR CIRED, Paris, France

${ }^{2}$ Sciences Po, Institute for Sustainable Development and International Relations (IDDRI), Paris, France

${ }^{3}$ AgroParisTech, ERFI, Université Montpellier 1, Montpellier, France
}

Corresponding Author:

Laurent Mermet, AgroParisTech, UMR CIRED, F-75015, Paris, France

Email: laurent.mermet@engref.agroparistech.fr 
Most of these complexities are already discussed to a certain degree by authors from both the evaluation and the environmental studies fields. The multiplicity of stakeholders and of expectations concerning policies, and the political and thus debatable ground on which evaluations rest, have been at the center of discussions since the late 1970s (Guba \& Lincoln, 1989) and are now also taken up by approaches that place deliberation at the center of evaluation (Cousins \& Earl, 1992; House \& Howe, 1998; United Nations Development Programme [UNDP], 1997). More recently, the com- plexity and uncertainties of the social and natural systems addressed by policies, the increasing com- plexity of policies themselves, and the prevalence of multilevel governance, with all the difficulties they create for evaluation, are widely recognized (although only partially treated) issues (Crabbé \& Leroy, 2008; Stame, 2004; Uusikylä \& Valovirta, 2004).

In our view, one main cause of difficulty in the evaluation of environmental policies is inadequately identified and treated: the high level of contradiction and conflict between environmental and other sectoral public policies. These contradictions are an essential basis of environmental policy; they currently reach high levels of intensity and take on new forms with contemporary changes in (inter alia environmental) politics and policy making. This results in specific challenges for policy evaluation. How is one to evaluate a policy when it conflicts, often directly, with other public policies with divergent goals and often more powerful resources? This is the crux of the approach to evaluation presented in this article. Its guiding principle is to use a clearly and strongly built focus on a specific policy concern (in our case, a given environmental concern) as a fulcrum for evaluation. By doing so, the evaluator can make the evaluation more relevant to environmental policy issues within the contradictory and conflicting context in which environmental policies are formulated and implemented. We developed this approach based on both our research on the theory of environmental management and policy (Mermet, Billé, Leroy, Narcy, \& Poux, 2005) and our experience in the analysis of environmental policies, especially through the three following policy evaluation works:

1. the 1994 evaluation of the French wetland policy, for which one of the authors was the lead consultant (Mermet, 1996);

2. an evaluation of how the policies of riparian countries and international donors on the Senegal River comply with their environmental commitments (Leroy, 2006);

3. an evaluation of several Integrated Coastal Management projects, programs, and policies both in Europe and within a development cooperation context (Billé, 2007).

The article will use the first two studies as examples.

The first section starts with a presentation of the specific problems contradictory policies raise for evaluation, particularly in the environmental field. This will reveal the need to reframe evaluation questions in an appropriate, specific way, to handle such evaluation situations. Based on the example of the 1994 wetland policies evaluation, the second section introduces the two complementary reframing efforts of the concern-focused approach: concentrating on a given concern clearly endorsed by the evaluator (rather than a comprehensive, ill determined set of concerns), and adopting a strategic approach to evaluation methodology (paying close attention when designing the methodology, both in terms of procedure and data treatment, to the active resistance the evaluation will have to overcome if it is to clarify outcomes on a given concern and their causes). A third section sums up the main steps of the concern-focused, strategy-driven evaluation approach, based on the example of the Senegal valley study. The fourth and final section is devoted to a discussion of the approach. It examines situations in which evaluators may opt for a concern-focused approach. It discusses when the approach may provide an alternative to, or a synergy with, some relevant and wellknown approaches from evaluation literature and practice. It looks at various possible roles for an evaluator adopting a concern-focused approach. Finally, the discussion shows how the proposed 
approach may be useful in improving the bridges between the evaluation community and environmental policy - a field requiring more evaluation. However, the lessons learned in that particular field might well be useful for evaluators of other policies too, in a world where the ambiguous treatment of contradictions between various policies is an increasingly important feature of politics and policies, at all scales, from local to international.

\section{Accounting for Conflicting Policies in a Context Where the Settlement of Contradictions Is Increasingly Deferred}

Conflicting with other policies is not an accidental but a fundamental trait of environmental policies. An environmental problem is a negative ecological consequence of some development activities. Sometimes, it may be treated by "end-of-pipe" solutions that do not critically challenge those activities. However, very often, its treatment requires problematic changes in development activities. Now, in most contexts, these activities are backed up by public policies that provide them with technical guidance and assistance, financial support in various forms, and political backing. Thus, as they endeavor to reorient environment-damaging activities, most environmental policies quickly reach the point where they contradict other sectoral policies. In many cases, these contradictions lead to complex, conflicting dynamic processes that affect profoundly the design, implementation, and outcomes of environmental policies. This intrinsic trait is reinforced by the fact that, as the last to have entered the game - compared to industrial, infrastructure, agricultural, transport policies, and others they have to contend with - environmental policies operate from a position of relative institutional weakness that is only gradually changing over time (Arts \& Leroy, 2006).

The fact that environmental policies often operate at cross purposes with other policies has been a key theme of the environmental field from the start. For policy evaluation, it is essential to realize that the way these differences in goals should be played out in public action has changed profoundly (in concept and in practice) over the last 40 years. In the 1960s and 1970s, environmental policy was accepted as being sectoral in some aspects, confined to its own area of competence (water purification stations, waste management), and in others, as confrontational, with a role centered on the critique, call to change and regulation of other sectoral policies (pollution control, rural landscape protection), or even sometimes as a combination of the two (as in biodiversity conservation and national park policy). With the 1980s came a major shift away from what was seen in retrospect as the "zero-sum game" of the 1970s environmental protection paradigm" (United Nations Conference on Environment and Development [UNCED] in Lafferty \& Hovden, 2003) and toward jointgain approaches that would promote both development and environmental goals. "Sustainable development" and "integrated management" or the "integration of environment into sectoral policies" serve as the organizing concepts of this currently hegemonic intellectual landscape. To achieve integration and search for joint gains, policy makers and policy analysts have been mainly looking toward more integrative decision-making procedures, with special importance given to public participation, and toward cross-sectoral, overarching integrated strategic plans (Lafferty \& Hovden, 2003).

Efforts in promoting integrative approaches are currently in full swing. It is time, however, to choose or design evaluation approaches that will be able to weigh their specific contribution and look at and beyond their limits. Four observations on the current context point to specific challenges in choosing the appropriate evaluation approaches. (a) The quest for joint gains can go only so far, and some important distributive issues ("hard choices") almost always remain. How the two are articulated (or not) in real environmental policy cases is an essential issue for evaluation. (b) The move toward integrated policies is also intrinsically limited. In any sort of organization, including 
policy-making institutions, integration balances, and is balanced by, differentiation of goals, missions, operating methods, and so on (Mintzberg, 1978). Issues concerning the differentiation of environmental policy must now be examined with the same care as issues concerning its integration. (c) Over the last decade, the effort to create processes for resolving contradictions between policies at various organizational and geographic levels (especially through integrative, participative procedures) has led decision makers to modify their political strategies. Increasingly, governments and policy makers simultaneously promote policies with conflicting goals and means (e.g., agricultural drainage and wetland conservation). In so doing, they defer the resolution of conflicts and contradictions, and they transfer the responsibility for settling these to other tiers and other moments of action and decision making. To other tiers, when they defer and transfer the treatment of contradictions to other, perhaps more participative, levels of governance and to other moments when they defer and transfer the treatment of contradictions further along the policy cycle that leads from policy making to (in principle, participative) implementation. Contradictory policies are adopted in the first place to serve constituencies with opposing claims or to address the contradictory concerns of the public (typically related to environmental protection vs. development based on environmentally damaging technology), in situations where the political costs of making a clear decision are considered too high. We see this deferred settlement of contradictions as a major trend in contemporary policy making. It enhances the role of policy evaluation as feedback into democratic debate (already underlined by Viveret, 1989). Indeed, as political choices become less explicit upfront, they need to be made more readable and more apparent down the line by examining the results of complex, "schizophrenic" sets of policies that have been concurrently implemented. (d) The development of participatory approaches, of approaches integrating concerns and constituencies, has also occurred in the policy evaluation field since the 1980s. It is important to realize, however, that the meaning and contribution of a given evaluation approach does change with the context. When one evaluates in a participative and integrative way a policy that lacked participation and integration, this may enhance both the critical and the formative potential of evaluation. When one uses participatory and integrative evaluation approaches on policies that used similar approaches in their design and implementation (involving the same stakeholders in similar discussion formats), there is a risk that the evaluation will simply provide more of the same and will essentially tend to reinforce and legitimize the policies. In such circumstances, it will be necessary to take a closer look at how to renew or complement the evaluation's basis for critical and formative added value.

This succinct review of the contradictions in policy aims and of the complex policy making and evaluation situations they create today questions the evaluator. What kind of evaluation is appropriate for this specific set of challenges? Let us start from what Vedung (1997), following Guba and Lincoln (1981), calls the "organizer": the logical point of departure of the evaluation. It depends on the answers to three basic questions:

1. On what concept of policies does the evaluation rest?

2. What criterion of merit is chosen as the basis of judgment?

3. By whom and for what kind of use are policies evaluated?

As there are several quite different appropriate possible answers to each of these questions, many coherent alternative approaches to evaluation have been defended and put to test by evaluators. Evaluation literature provides some good inventories, from the most systematic (Stufflebeam, 2001) to the rather ironic (Pawson \& Tilley, 1997, pp. 1, 2). Crabbé and Leroy (2008) systematically review 22 approaches and examine how each one can contribute to the evaluation of environmental policy. We cannot summarize such a systematic inventory here but will return to some relevant approaches in the discussion section of the article. For now, we will just agree with Crabbé and Leroy that the existing approaches can make many useful contributions but that some important issues are inadequately treated. 
The concern-focused approach covers one such issue (ambiguity and contradictions). It consists in focusing first on a given policy concern, then on the set of policies that affect that concern and finally, within that set, on the contribution of a given plan, program, or policy ${ }^{1}$ that addresses that concern. This is the method we propose for reaching beyond what we see as an impossible choice of alternatives, which Crabbé and Leroy (2008) summarize as "goal-oriented or goal-seeking?" If programs are ever more ambiguous, complex, and interwoven with other programs, evaluating one program more or less directly according to its goal raises growing difficulties, despite the rich contributions and debates of the evaluation community on that issue. However, if one accepts that policies redefine goals as they go, and that evaluations too may redefine goals as they proceed in a participatory manner, one may run the dual risk of (a) the evaluation failing to give clear feedback on policy achievements in view of political commitments and of (b) the most powerful actors influencing the evaluation process so as to evade clear answers on certain policy goals that are essential to other stakeholders, in evaluation situations involving a marked asymmetry of power. This is an impasse we often meet when analyzing cases in environmental management and policy. To get out of it, we propose the following "organizer" for the evaluation.

1. On what concept of policy does the evaluation rest? Policies are activities aiming to resolve or alleviate specific concerns that have been expressed by constituents and on which political decision makers have committed themselves. We define as "actual" or "de facto" policy vis-à-vis a given concern the set of public policies that affect the outcome regarding that concern and commitment. We define as "intentional" policy those policies, which have that particular concern as their (or one of their) main aims. This dual concept of policy is based on our "strategic environmental management analysis" framework (Mermet et al., 2005). By embracing the whole set of policies that shape the outcome for a given concern before examining the contribution of a given intentional policy, it frames the analysis in a way that helps take up many of the challenges raised by contradictory policies and their complex dynamics.

2. What criterion of merit is chosen as the basis of judgment? The evaluation rests on one focal concern (or a compact, restricted set of closely related concerns). Policies that affect that concern are judged according to their impact on it. The contribution of policies that aim to treat that concern is assessed in full view of the whole set of public policies shaping the outcome relative to that concern, whether intentionally or not. This allows for clear answers to public policy concerns and evaluation of the fulfillment of political commitments, even in contexts of multiple policies, with multiple aims and complex design and implementation processes. The cost is simply that one has to limit oneself to evaluating one concern at a time.

3. By whom and for what kind of use is the policy evaluated? As will be clear with the examples and discussion, this will be subject to a great diversity of strategic situations and methodological designs. For now, let us just state that by providing a firm grip on a given "stake" (concern), the evaluation sets out to help those "stakeholders" that are interested in that particular stake and in the political commitments that are made (or eluded) about it.

This organizing framework rests on a fundamental choice regarding the way the evaluator connects strategic choices in terms of process and of substance. Whether he or she generally professes the (epistemological, methodological, and practical) primacy of process or of substance in evaluation, a decisive part of the evaluator's craft is to master technical and tactical ways of leveraging substance on process, and process on substance. By firmly anchoring the evaluation in the substance of a given concern, the concern-focused approach provides a basis for methodological moves-including, and perhaps even especially, in terms of process - that can cut through (or take up) the strategic challenges that contradictory and ambiguous policies increasingly present to the relevance of evaluation procedures. This is why we see our approach as both strategy-driven and concern-focused. 


\section{Focusing on a Given Concern, Designing the Evaluation Strategically}

To further explain the approach, let us turn to an example: the evaluation of French wetlands policy that led to its first design and use (Mermet, 1996).

Wetlands are environmentally valuable: they play an important role in sustaining biodiversity, in providing water resources and ensuring water quality, in limiting the impacts of floods, and in conserving rural landscapes, and so on (Mitsch \& Gosselink, 2007). At the onset of the evaluation (1993), wetlands conservation in France — as in many countries_-involved a large number of public actions aimed at limiting or halting their alteration. However, environmental actors, both governmental and nongovernmental, sharing a concern for wetlands, had experienced considerable difficulty in implementing those initiatives. They had gathered much anecdotal evidence of widescale wetland degradation and of its causes, particularly agricultural drainage and dredging and filling for development and infrastructure. When a new policy evaluation procedure was instituted in 1990 (decree dated January 22, 1990), which allowed one ministry to initiate an evaluation of an interministerial policy, the Ministry of Environment took the opportunity to launch an evaluation of wetland policy as a whole. Like all evaluations under that procedure, it was led by an "ad hoc evaluation committee," which based its work on evaluation studies it commissioned, conducted by external evaluators. The report was published in 1994 (CIME, 1994), after being reviewed by both the expert and the political committees established by the 1990 decree to supervise the work of the various ad hoc evaluation committees.

\section{A Strategy-Driven Approach}

The evaluation team first had to appraise the strategic situation created by the evaluation. From the heterogeneous and incomplete information available, it was clear that the Ministries of Agriculture and of Public Works, whose policies were thought to have major impacts on wetlands, had reasons for active strategic resistance to the evaluation. Their attempt to affect the evaluation procedure by staying away from meetings was countered by the strong political intervention of the chairman of the ad hoc evaluation committee. Of more relevance here were the argumentative tactics they used during the evaluation process, to foster ambiguity and uncertainty on wetland degradation and on their responsibilities therein. Conducting the evaluation in a strategic way meant defining the questions and the methodology so as to generate results that would not only have intrinsic merit (quality of data, coherence of method, etc.) but that would resist specific arguments aimed at producing uncertainty (Mermet \& Benhammou, 2005). Three examples will illustrate this strategic dimension of methodological design.

Farming, through drainage and the conversion of pastures to arable land, often has negative effects on wetlands and their environmental condition. It can also have positive effects by maintaining extensive pastures with high biodiversity, landscape, and water management values. Although French and European agricultural policies devoted considerable resources to intensification and only limited resources to maintaining extensive systems, officials from the Ministry of Agriculture claimed that the effect of its policies on wetlands was neutral or uncertain, being sometimes negative and sometimes positive. The evaluation methodology was thus designed to rest on a large list of wetlands, which were reviewed to count the cases where agricultural development policies had a positive effect and those where it had a negative one.

Available data on wetlands, activities and impacts, were abundant but very heterogeneous. Good quantitative data were available on some wetlands for certain issues. For other issues and other wetlands, the evaluation had to rely on expert advice based on various kinds of studies. For each wetland in the list, the same questionnaire was completed independently by two experts, who were asked to base their assessments on the best available data. The questionnaires were then compared, 
cross-checked, and synthesized by scientists who were members of the ad hoc evaluation committee. Officials from the Ministry of Agriculture then attempted to reject these results, invoking the need for scientific rigor. They first insisted on data requirements for the evaluation that were simply unattainable. Doing so gave them a good chance of preserving the status quo of uncertainty, despite the abundance of available information. When it was clearly reaffirmed that the aim of the evaluation was to obtain the most objective picture of policies based on best available data and expertise, they then contested the competence or the neutrality of experts, so as to discredit the results. For instance, they denounced the fact that many experts had previously worked on Ministry of Environmentfunded studies. Because the other ministries fund almost no work on wetlands, accepting such an argument would ruin any realistic hope of evaluation. The methodology was adapted, so as to allow any stakeholder disagreeing with questionnaire entries on some of the wetlands in the sample to file a counterexpertise for those wetlands. These would be discussed on their merits by the ad hoc evaluation committee, on a par with the two questionnaires completed by the experts initially commissioned by the committee. Eventually, challenges to the results were few and had little impact on the overall findings of the evaluation.

The evaluators were also aware, however, that forcing the Ministry of Agriculture to admit that wetland conservation policy have had only limited results largely due to the massive negative impact of agricultural development policies would not be the end of the story. Indeed, officials from the ministry could then have resorted to one of the most widespread arguments in environmental controversies: "Yes, we admit that our actions up to now have been detrimental; however, our orientations and methods have changed (witness this or that recent directive or ministerial discourse); it is too early to observe results, but from now on, criticism of our former actions is irrelevant." This argument is potentially devastating for any evaluation, because it can declare irrelevant the results of even the most careful analysis of past and current policies. The methodological response to this risk was to include in the survey, for each wetland in the list, a series of criteria regarding the prospects for degradation, stabilization, or restoration of the wetland's ecological conditions in the coming years. If a change in sector-based policies and their impacts on wetlands was underway, that would have to be demonstrated based on evidence from the ground and from a large number of cases, not just from grand statements of intention.

It is essential to note that each of these choices of methodological design, which proved decisive in the clarity and impact of the evaluation's results, was the object of an intense and strategic negotiation, where the evaluators repeatedly faced resistance from groups whose actions, activities, and policies were at odds with the objectives of wetland policy.

\section{A Concern-Focused Approach}

Besides being alert to the strategic dimension of the evaluation procedure and methodology, the evaluators also had to set questions and methods relevant to a situation of multiple contradictory policies affecting wetlands.

Because environmental policies aim at an outcome that can be expressed in terms of the condition of given ecosystems, the evaluation was firmly centered on the question that expressed this environmental concern: do existing policies make it possible to stabilize and perhaps restore the ecological condition of wetlands? Its first focus was to obtain as clear a picture as possible of how the ecological condition of wetlands had been evolving over the last 30 years. Therefore, an important part of the survey questionnaire was designed to obtain data and expert advice to that effect on each of the wetlands in the list.

Only when the issues and modifications in the ecological conditions of the wetland had been adequately described, were the experts asked about the causes of such modifications. They were asked to identify which human actions had contributed to "damaging processes" that had caused 
modifications in the ecological condition of the wetland, and when. Among these actions, they were required to identify which public policies had played a role. The questionnaire distinguished between policies explicitly aimed at wetland conservation and others. It did not, however, pre-identify which sector-based policies may have caused modifications in the wetland's ecological condition.

The survey questionnaires, once completed, cross-checked, and synthesized, provided precisely the kind of information required by the concern-focused framework. How did the ecological condition of French wetlands (the "concern" at the basis of wetland conservation) change? What set of policies (composing the "de facto" wetland policy) had been responsible for those changes? What actions had been implemented with wetland conservation as their specific objective ("intentional" policy), and what had their contribution been to the overall outcome? One recognizes the "organizing" choices of concern-focused evaluation (a) to focus on given environmental outcomes, (b) to hold accountable all policies that have an impact, negative or positive, on these outcomes, and (c) to examine policies with explicit environmental goals within this wider picture.

The results spoke for themselves. In the 30 years preceding the evaluation, of the 76 wetlands in the list (which included the most important French wetlands), 12 had suffered major damage, 53 had undergone significant damage, 8 had been more or less stable, and 3 had seen their environmental condition improved. Clearly identified public policies - such as support for drainage, filling for development and infrastructure, permitting of quarries, and subsidies for planting conifers in peat bogs, and so on-were identified as the main causes of such transformations in wetlands. Some 65 wetlands had suffered negative impacts from policies administered by the Ministry of Agriculture; 39 by policies from the Ministry of Public Works or from local and regional authorities; and 20 by policies (including permitting procedures) administered by the Ministry of Industry. The evaluation also showed that there was only a small difference between the period 1960-1980 (when there were no clear commitments or policies about wetlands) and 1980-1990 (when no sector- based policy operator could claim not to be informed about wetland issues and policies). Policies aimed at conserving wetlands were shown to absorb approximately one half of conservation funding in France. The main ones (various programs to establish conservation areas by buying land or through regulations) covered approximately $7 \%$ of the total area of wetlands in the list. As for the possible changes over the following 10 years, it showed that 19 wetlands could reasonably be expected to be stabilized in terms of environmental quality, 19 could not, and the remaining 36 had uncertain prospects, largely depending on the mix of public policies they would be submitted to in the next decade. So the evaluation established that the situation was potentially more promising than the one in the previous decades, but that a stabilization of wetlands was out of reach for the imme- diate and medium-term future, even considering potentially ambitious conservation policies.

Compared with other evaluations launched under the same evaluation procedure, this one had a particularly significant impact on policy making (Lascoumes \& Setbon, 1996). After publication of the report in the spring of 1994, results were discussed in a large-scale seminar the same year, and the government launched a "national wetland action plan" in May 1995. Among other measures, the plan included features such as a review of existing laws, so as to suppress rules that made the destruction of wetlands compulsory (for instance, articles in the rural code that made it compulsory for landowners to use wetlands for agricultural production or to lease them) or encouraged it (especially through heavier taxation on meadows than on arable land in many cases).

The approach and methodology of the evaluation, however, puzzled the committee of experts supervising evaluations based on the 1990 decree, as well as independent observers (Lascoumes \& Setbon, 1996), who found it closer to an impact study than to a classic policy evaluation. Such differences will be discussed in a further section of this article, but the impact on policy making was, we think, an indication of the usefulness of focusing on a given concern and on a strategic choice of methodology. 


\section{The Four Steps of the Approach}

These organizing choices, however, lead to serious challenges for the design and implementation of the evaluation. In this section, we will review them as they successively present themselves in the four steps of a concern-focused evaluation:

1. defining the focal concern

2. developing criteria and synthesizing observed variations in environmental quality

3. identifying policies that contribute to the concerns being met or not

4. evaluating policies specifically aimed at meeting environmental commitments.

As an example, we will take Maya Leroy's evaluative research on the implementation of international environmental commitments in the Senegal River valley (Leroy, 2006).

The Senegal River, 1,700 km long, is shared between four main riparian states: Senegal, Mauritania, Mali, and Guinea. It flows through mostly dryland. Yearly floods create complex aquatic and terrestrial habitats that are essential for biodiversity, fisheries, grazing, and traditional flood recession agriculture. In the late 1980s, two dams were built. The Manantali reservoir is located upstream in Mali on the Bafing, the main tributary of the Senegal River, which contributes 50\% of the flow. It has the capacity to store 11 billion $\mathrm{m}^{3}$ of the strongly seasonal rainfall on the Fouta Djalon Mountains in Guinea. The water is subsequently released in the dry season to serve three main goals: the development of irrigated agriculture on hundreds of thousands of hectares of former floodplain, the production of electricity, and river navigation. In the river's estuary, the Diama dam blocks salt water from flowing up the river, making it possible to use water for irrigation and urban supply. The Manantali dam was funded by international donors and was the object of intense international controversy and of elaborate environmental impact studies in the 1970s. It is managed by the Organisation pour la Mise en Valeur du Fleuve Senegal (OMVS; the Organization for the Economic Development of the Senegal Valley), a three-state international body whose members are Mali, Senegal, and Mauritania. The organization currently plans, with the help of international donors, to enhance the electricity production capacity of the dam. Doing so will modify water flows, especially the annual flood regime and the ecological mechanisms relying on it. An "environmental impact mitigation plan," the PASIE, is the most visible environmental program in this context. Leroy conducted the evaluation essentially as an independent evaluative research project. It had theoretical and methodological aims to further develop the concern-focused, strategy-driven evaluation approach. It also pursued substantive and strategic goals: providing an evaluative analysis of wetlands and biodiversity management in the Senegal River valley, which was lacking in the ongoing academic, expert, and policy debate.

\section{Defining the Focal Concern}

Building and managing dams has a major impact on river ecosystems. It affects the extent and functioning of riparian wetlands, the quality of aquatic ecosystems, the fisheries, as well as the livelihoods derived from traditional activities in these ecosystems (World Commission on Dams, 2000). Such concerns, repeatedly expressed over decades by scientists, environmental nongovernmental organizations (NGOs), and environmental agencies, have been translated into commitments by states. Most relevant here are the Ramsar Convention on the conservation and "wise use" of wetlands and the Convention on Biological Diversity, addressing biodiversity conservation and sustainable use. The riparian states of the Senegal River are parties to both conventions. They also have national legislations for the conservation of wetlands and biodiversity. A first step of the evaluative research was to define clearly and precisely what concern would provide the normative cornerstone, 
the ecological "criteria of merit" that would give this particular evaluation its meaning. For the researcher, this is both a technically and a strategically demanding task. Concerns and commitments are embedded in abundant and heterogeneous texts (legal documents, political statements, academic publications, expert reports, and advocacy pamphlets), which are often technically sophisticated and laden with both contradiction and ambiguity. Here, the evaluator defined the concern by five fundamental principles, the three most important being: (a) maintaining a regime of sufficient annual flood, (b) refraining from developments that hinder the lateral circulation of water in the valley, and (c) supporting human activities that rely on and maintain ecosystem services provided by wetlands. A policy that does not address such concerns simply cannot meet the expectations expressed by environmental organizations nor comply with the political commitments of states and donors under the Ramsar and Biodiversity conventions.

Responsibility for the precise definition of such a set of concerns rests with the researcher/ evaluator. From an academic point of view, it is to be taken as the axiomatic question, the problématique, which will condition the evaluation's worth and meaning-just as it would in any other kind of social science research. From an evaluative point of view, it is neither a simple transcription of legal commitments nor does it slavishly take up the demands of environmental groups. The central idea here is that public policies are fundamentally about fulfilling political commitments intended to meet needs expressed by civil society: it is this meeting point of expressed societal needs or claims and political commitments that we call the "focal concern." The better the researcher manages to pinpoint it — or rather, to posit it—in a precise and relevant manner, the more likely it is that his research will be both strategically relevant as an evaluation intervention and academically robust.

\section{Developing Criteria and Synthesizing Observed Variations in Environmental Quality}

Once the focal concern has been laid down, the evaluator has to turn it into workable, precise criteria for the evaluation, and to gather the data that will inform these. For instance, how long, intense, and frequent would an annual flood have to be, in order to be considered sufficient to support wetland ecosystems and wetland-based human activities? Here, most of the "data" comes in the form of (often overabundant, yet still incomplete) expert literature, replete with controversies caused by differences in definitions and views, uncertainties, heterogeneous sources, and methods. Again, the evaluator will have to make choices. The guiding principle is to establish criteria that will be as robust as possible in the context of the strategic controversy that the evaluation will trigger, if it is to be used. They will also have to be workable in terms of data availability.

In this context, it is our view that strategic and scientific considerations, far from diverging, actually tend to converge. It is hard to conceive of criteria that would resist the controversy, while being weak relative to the state of the art concerning the issue. If the evaluator, for instance, suspects that existing policies fall short of the commitments they ought to meet, it is surely not in his strategic interest to define unreasonably demanding criteria. Criteria that are as difficult as possible to contradict will serve much better both the strategic and the academic purposes of the evaluation.

Defining such criteria and finding the data to assess to what extent they have been met is a demanding task. In most environmental cases, the volume and complexity of the available data are rather formidable. The task also requires a mix of very different skills: scientific (here, hydrological, ecological, etc.), technical (here, dam management and hydraulics, agricultural production), managerial and legal (laws, decrees, guidelines, etc.), anthropological, and political. This is a challenge shared by most evaluation approaches in the environmental field (Mickwitz, 2003). Strategically setting clear guidelines and relying on an explicit focal concern will help navigate these difficult waters. It will not, however, be a substitute for sufficient resources or for an adequate mix of com- petencies within the evaluation team. 


\section{Identifying Policies That Contribute to the Concerns Being Met or Not}

Once the focal concerns are well defined and one has a good idea of whether and to what extent they are met, the evaluator must ascertain the causes of this outcome. These can be natural (for instance, riverbed dynamics preventing a wetland from being flooded) or anthropogenic causes (for instance, damming seasonal flooding). Such human activities can be the direct result of public policies (for instance, a publicly funded and engineered dam project), the indirect result of such policies (for instance, damming by private operators encouraged by subsidies), or may not be clearly linked to policies (for instance, a farmer draining his land without specific incentives). Once he has thus described the "de facto" management of the focal concern, if he organizes the analysis in such a way that the contributions of public policies are shown as clearly as possible, the evaluator can present a readable and coherent overall picture of the set of policies that contribute significantly to this outcome.

At first sight, this may seem like an impossible proposition, given the complexity of most environmental issues. Our field research shows, however, that most of the time a systematic review of the causes of ecological conditions reveals that among a large inventory of involved policies, a small number often accounts for most of the outcomes. Such crucial, decisive policies were identified in the case of the Senegal River: management of water flow from the Manantali dam by the OMVS, micro-hydraulic programs along the riverside, the very unequal support given, respectively, to irrigated agriculture and to traditional, ecosystem services-based farming and range management. The initiation, design, funding, and implementation of these crucial policies can be, and must be, clearly identified. In the Senegal River management evaluation, this led back essentially to the same operators (states and international donors) who have made the environmental commitments that are the focus of the evaluation. In this case, it is clear that most of the OMVS plans for hydroelectric production and the national authorities' plans for hydraulic work and irrigation would potentially have very negative effects regarding such environmental commitments.

\section{Evaluating Policies Specifically Aimed at Meeting Environmental Commitments}

As a counterpoint to identifying policies with the most decisive impact on ecosystems, the evaluator will have to identify and evaluate those that have the focal (environmental) concern as their main goal. They may intersect with other, decisive policies to a high degree, to a moderate degree, or hardly at all. How much and to what effect they do is of course of paramount importance for the evaluation: what exactly is the contribution of environmental policies to the overall management of the environmental concern at the center of the evaluation?

In the case of the Senegal River, the most obvious and important such policy was the "environmental impact mitigation plan" (PASIE), identified by states and donors as the main tool for meeting environmental commitments, and which used most of the environment-targeted funding. The evaluator examined the design and implementation of the plan. Of its six target areas, only one, "optimization of reservoir management," was found to be relevant to the focal concerns. The five others (mitigating direct impacts of building the new powerplant, bringing electricity to rural villages, etc.) had interesting objectives but were quite remote from the environmental issues of the valley. On closer examination of the implementation of that one relevant target area, it was found that it was the least funded of the six and that a succession of negotiated compromises and technical difficulties meant it was going to have very little impact on the central environmental issue. Initially stated intentions to optimize the annual flood vital to wetlands and wetland-based sustainable activities, by increasing dam releases and synchronizing them with natural floods of major tributaries, were abandoned. The maintenance of the flood was envisaged only for a limited time span of 20 years: irrigated agriculture is expected by the plan's authors to have developed enough by the end of that period to make ecosystem-based agriculture redundant. There were also plans to intensify 
flood recession agriculture during that transitional period through local hydraulic works that would make it less dependent on the natural functioning of wetland ecosystems and the services they provide. All these elements run in clear contradiction with the environmental commitments made by riparian states and international donors, as recalled by the focal concerns of the evaluation.

To sum up, the OMVS is now planning to maintain a fixed-date annual flood through water release from the dam. This decision is mainly the result of intense political pressure from local and regional authorities along the valley, motivated by the fact that the livelihoods of many communities depend on annual flooding (for traditional agriculture, cattle raising, and fisheries). The contribution of the PASIE to this partial meeting of environmental commitments can only be evaluated as marginal.

Again, a relevant evaluation of policies such as the PASIE, aimed at environmental goals in the context of wider public action, can only be obtained by combining an evaluation of the plan per se (its administration, outputs, and impacts) and a wider evaluation that clearly establishes its place, role, and contribution within the overall de facto, actual, public management of the ecosystem, which is at the heart of societal expectations, of political commitments, and of the evaluation.

\section{Discussion}

\section{Evaluation Situations Where the Approach May be Relevant}

The raison d'être of the concern-focused approach is to help overcome two evaluation challenges: (a) evaluating policies whose implementation and outcomes are severely negatively affected by other, contradictory, policies and (b) overcoming the ambiguities of complex, integrated, highly procedural policies to establish whether they deliver expected outcomes on specific commitments. Obviously, the approach is relevant mostly in evaluation situations where these two challenges are central.

This is not the case, for instance, for well-established, clearly sectoral environmental policies, such as programs to equip towns or industries with water pollution treatment installations. Such cases may present great challenges to evaluation because of long time frames, complexity, geographical specificities, and the importance of science and scientific uncertainty (Mickwitz, 2003), but because ambiguity and conflict with other policies are not crucial issues, concern-focused evaluation is of no particular relevance here.

Neither would it be relevant in many situations where policy makers or the clients of an evaluation essentially want to get all the parties around the same table, to build joint solutions to a policy problem, and to identify and handle difficulties together through evaluation. Such approaches have been a major focus of both research and policy making in the last 20 years, and these "all parties around the table" situations have thus become extremely common in environmental-and otherpolicies. If one assumes the stakeholders share sufficient motivation to define and solve environmental problems together and to overcome their differences, then there is little need for a concern-focused approach. It may be better to allow (and to help) the stakeholders themselves to identify the policy improvements they want.

Concern-focused evaluation may be of particular relevance in three other types of situations. The first could be labeled "ambiguity around the policy table." This situation occurs when "all around the table" forms and procedures of policy making and evaluation are applied, but asymmetries of power persist to a degree where such forms of procedure may function as a strategic device to continue with contradictory policies and to generate more ambiguity. In our work, we have often come across situations of this type (Mermet, Dubien, Emerit, \& Laurans, 2004). Dealing with them seriously and in a specific manner will be an increasingly important challenge for environmental policy evaluation in the coming years. Here, concern-focused evaluation can be highly useful: as 
contradictions and ambiguities become deeper and come in forms that are ever harder to clarify, they require a competent and specific evaluation effort. Of course, there are gradients between bona fide and manipulative "around the table" policy and evaluation situations. Where a given case belongs is also largely open to multiple interpretations. One of the benefits of concern-focused evaluation in situations of ambiguous cooperative policy is that, as it pushes for clarification of the extent to which the outcomes of a joint policy arrangement do meet a given concern, the reactions the evaluation sparks off from "around the table" can provide very useful evaluative information on the actual commitments and strategies of the parties.

A second type of situation lies at the other end of the spectrum. Here, we find environmental policy commitments that do contradict other powerful policies and are "orphan" (they lack operational support within the administration and from adequately structured civil society groups), marginalized (the stakeholders have very limited power within the administration and civil society), or "diluted" (the commitment involves many stakeholders and policy operators, but it is low on each one's priority list and they can be dispersed institutionally or geographically). The Senegal valley case provides a good example of a situation dominated by such problems. Here, power asymmetry is such that it would be extremely difficult to launch an evaluation that would be directly commissioned and sanctioned by the authorities and the stakeholders. In such situations, the concern-focused approach provides the basis for an alternative route for evaluation, where the legitimacy of a given policy concern and political commitment gives the evaluator a fulcrum on which to leverage a strategic process of evaluative study that may help evaluate policies, as it were, against institutional odds, and feed that evaluation back into the political and policy-making debate.

In a third type of situation, an environmental policy may have enough (administrative and civil society) support to make more official, commissioned evaluation possible, but the asymmetries of power may still be such that they make it difficult for the evaluator to bring the evaluation to a clear conclusion. The evaluation of French wetland policies is a good illustration of such a situation. Here, the concern-focused approach provides a complementary anchoring point that strengthens the evaluator's situation in the course of various types of evaluation procedures.

\section{A Complement or an Alternative to Other Change-Oriented Evaluation Approaches}

Depending on the situation, concern-focused evaluation may provide a complement or an alternative to other evaluation approaches. Let us examine how it stands in relation to some tested approaches, starting with the last two types of situations we just presented. Here would be the domain of evaluation approaches that are essentially change oriented, where the evaluator sees his role mostly as providing material and evaluation processes to support those actors that are motivated to change the policy, and the situation it addresses, in a specific direction.

An important remark here is that, as they developed since the mid-1970s, most such approaches put their emphasis on the evaluation process, promoting, for instance, stakeholder involvement or some parties' access to the policy debate. Because the concern-focused approach mostly aims at finding leverage in substance, there is no dichotomy that would force the evaluator to choose between a concern-focused and another, essentially procedural, approach. In many cases, the evaluator may find an advantage in combining the move we advocate here of focusing on a given concern with a procedural strategy guided by another evaluation approach. Of course, the possibility and relevance of such combinations depends closely on the strategic circumstances of each evaluation situation.

The strategic drive in our approach owes much to Patton's (1986) "Utilization-focused evaluation." In fact, our first example here (French wetlands policy) could also qualify as "utilization focused." By keeping close contact with and strengthening the network of administration and civil society organizations for wetland conservation, it did indeed "aim at the interests and information 
needs of specific, identifiable people - not vague, passive audiences." And as "intended evaluation users," they were "personally and actively involved in making decisions about the evaluation" (Patton, 1986, p. 57). Here, there was real synergy between the utilization- and the concernfocused choices in the evaluation, in that by pushing (especially in methodological choices) for stronger concern-focus, we really helped the intended users to push their way strategically through the evaluation procedure.

The example of the Senegal River, however, exemplifies other situations where groups supporting environmental policy and commitments are absent, very weak, or too dispersed to serve as a user group on which the evaluator could rely. To serve such "disempowered citizens," empowerment evaluation may come to mind. However, the principles of empowerment evaluation and their discussion (Fetterman \& Wandersman, 2007; Miller \& Campbell, 2006) mostly point to situations where a rather marginalized community implementing a policy is both in need of more resources to build its capacity and autonomous enough to take in hand the evaluation process with the evaluator's help. If we take as an example, a wildlife conservation service in a difficult situation focusing the evaluation on the specific environmental outcomes that justify the group's action may be a useful complement to empowering procedural approaches to evaluation of policies that group is serving. However, only a fraction of environmental policy situations would qualify for such an approach and many of the most difficult ones would not. When the asymmetry of power is very strong, there is often considerable strategic advantage in choosing indirect forms of strategic support and alliance to support the most disempowered. This is the "alternative route" that the concern-focused approach can contribute in such cases. It brings support to those citizens and groups who have the concern, not so much by engaging them in, and empowering them through, the evaluation process (or procedure) itself, but mostly by contributing robust evaluation results focused on their concern, which may provide an important resource for their efforts. Decoupling to a certain extent the substantive from the procedural can be a strategic move. It addresses those situations where weak, dispersed, threatened, or ambivalent groups are in situations of vulnerability where it may be problematic for them to become more visible to their powerful opponents. Here, evaluation focusing on procedure and involving stakeholders very explicitly may be strategically counterproductive, and focusing on the concern of marginal groups, rather than involving them publicly, may be a sound route for evaluation.

If evaluation is really strategic, that is, if when claiming empowerment it is "aimed explicitly at and therefore to be judged by its effectiveness in altering power relationships" (Patton, 1997), then it cannot adopt in advance a fixed strategic procedural plan and method. The essence of strategy is to adapt method to situation in a way that will make moves as powerful as possible relative to means and that will make countermoves difficult (inter alia, by not being too predictable). So the fact that there is a whole repertoire of "participatory, collaborative, stakeholder-involving, and utilizationfocused approaches to evaluation" (Patton, 1997) is a strength of the evaluation field. Leaving open the choice of procedural approach allows strategic flexibility in the face of evaluation situations that are very different strategically. What we are claiming is that in many cases, a deliberate and determined focus on a given concern, sometimes even associated with strategically feigned innocence with regard to stakeholder and procedural issues, may provide useful strategic leverage to empower weaker stakeholders with specific concerns. The combination of that leverage with other changeoriented approaches to the evaluation process must be guided by the strategic specifics of each evaluation situation.

\section{The Locus of Pluralist Debate: What Relations With Participatory and Consensus-Building Evaluation Approaches?}

Turning now to the relations of the concern-focused approach with the first type of situation"around the table," consensus-seeking evaluations - and the corresponding evaluation approaches, 
we keep in mind that the whole environmental policy field and discourse are moving massively in that direction and that identifying their limits is a major issue for contemporary evaluation.

With responsive evaluation, the field of evaluation in the 1970s participated in the collective rediscovery of the fact that the diversity of stakeholders' views is not reducible to an equation, that views from the ground are an indispensable complement to data treatment, and that there are limits to the rationalization of management and policy through methods that too closely mimic hard science (Abma \& Stake, 2001; Greene \& Abma, 2001). Thirty five years later, many of these core ideas have become fundamental tenets of numerous evaluation approaches, including ours. They have also pervaded the practice of policy making and implementation. In recent years, the voice of local stakeholders (farmers, various industries, environmental groups, etc.) has become so loud about any environmental policy move that choosing not to be responsive is no longer an option. In this new, quite different context, we see the issue and the contribution of concern-focused evaluation as helping to balance responsiveness to all stakeholders and assertiveness of certain policy concerns and commitments.

Starting a few years later, with the publication in the late 1970s of Holling's book on "Adaptive Environmental Assessment and Management" (Holling, 1978), another movement of thought sought the involvement of stakeholders in policy design and evaluation through their collective participation in computer modeling exercises. This is, for instance, the basis for mediated modeling (van den Belt, 2004) or for the "companion modeling" approach (Collectif ComMod, 2005) that has rapidly developed in France over the last few years. As ours does, these approaches use content treatment as leverage to move forward with the evaluation process. They seek, however, to build consensus and so help stakeholders evaluate and decide collectively on policy matters that concern them. In our view, they are relevant only for those evaluation situations where the asymmetry of power remains limited (or is not exploited strategically) and where there is already sufficient potential for bona fide cooperation on a given environmental issue. The concern-focused approach is more relevant where consensus-building processes are too vulnerable to power play and manipulation. In addition, we note that many consensus-building modeling approaches rely on a given (modeling) toolkit for the treatment of content. Complex and strategic evaluation situations present so many constraints (both in process and in data acquisition and treatment) that it may be more useful not to restrict oneself in advance to a limited repertoire of investigation methods, data treatment, and establishment of proof.

Belonging to yet another movement of thought, the Deliberative Democratic Evaluation of House and Howe (House \& Howe, 1998) uses contemporary deliberative theories (Manin, 1987) as the basis for collectively constructing evaluations that can be endorsed by stakeholders with differing views. The quest for objectivity through a ruled confrontation of views and the consideration given to all arguments irrespective of the power wielded by participants in the deliberation are important contributions of such contemporary approaches. Still, in practice they are relevant for those situations with sufficient potential for truly collaborative policy making. We would concur with the concern vigorously expressed about them by Crabbé and Leroy, that if "there is a power imbalance between the actors, and one ... decides to veto a decision, the evaluation process is in danger of grinding to a standstill" (p. 155).

It is precisely such blockages that the concern-focused approach sets out to counter. It does so, not by a return to a technocratic model of decision making or evaluation, but by taking into consideration how much strategizing it takes to actually get a given evaluative issue (in our case, an environmental one) to be truly discussed in political and policy-making forums. The many evaluation approaches that foster pluralistic debate within the evaluation - in France, for instance, "evaluation pluraliste" (Monnier, 1992) - may contribute a great deal in that direction by providing occasions for informed discussion between stakeholders. We think, however, that it is important not to restrict the quest for pluralism to the arenas the evaluator himself can organize. Sometimes, it is best (or even the only viable option) to arrange the evaluation so as to trigger intense debate elsewhere, 
in a place less vulnerable to blockage and more influential on policy. Just as the "locus of control" of an evaluation can productively shift (Themessl-Huber \& Grutsch, 2003), the evaluator ought to be able to strategically play with the locus of debate, the locus of pluralistic confrontation, within, around, and beyond the evaluation process itself. In our field, we concur here with Lehtonen (2006) in thinking that this role may often be best served by evaluations clearly concentrating on given environmental concerns.

\section{Roles, Repertoires, and Connections of the Concern-Focused Evaluator}

Given the diversity of evaluation situations and procedures where a concern-focused approach may be appropriate, the roles taken up by the concern-focused evaluator may differ considerably according to context.

Where the concern-focused approach is adopted in the framework of one or another standard, commissioned, evaluation procedure, the evaluator has to both manage the evaluation process and ensure strong and strategically appropriate methodological treatment of the substance of the case relevant to the focal concern. Even these more standard situations are very diverse in terms of the conditions they create for clear answers on a given concern. So, it is a good thing for the evaluator to be able to mobilize a diversity of methodological resources, both on procedure and on substance. Conversely, the concern-focused approach may complement the already rich toolbox of adaptable, strategic evaluators.

A particular problem arises when the evaluator finds himself committed to a consensus-building process of evaluation which, he gradually realizes, tends to evade precisely the public concern and political commitment ostensibly central to the policy and the evaluation. A concern-focused approach can then sometimes be used strategically to push such a central concern back into the collective evaluation process. It may also help the evaluator to break with the process and take up the role of critical policy analyst. Such increasingly frequent situations, where process clashes with substance, may be awkward, as the role of the evaluator is in tension between, on one hand, contractual obligations and deontological norms, and on the other hand, personal or professional commitments to given public concerns. Here, there is no general solution, but clearly articulating the focus, on process and/or on concern, can help to either find ways to combine both or to make hard choices in an explicit way.

Cases where the concern-focused approach is used to open an alternative route call for yet another set of roles that may be less familiar to the evaluator. Here, evaluation borders on evaluative research or studies. As he enlarges his scope, the evaluator still has many useful reference marks to find in (and to contribute to) the evaluation literature, but he must also connect closely with other fields of study, especially (a) critical research on policies and (b) specialized studies in the field relevant to the focal concern (in our case: environmental studies). (a) The academic disciplines that support critical analysis of policies are essential connections for three reasons. First, they provide many useful intellectual resources to help unravel extremely complex and ambiguous policy situations and processes. Next, on a tactical level, academia can provide institutional shelter and organizational resources for noncommissioned and critical evaluation work. Third, academic arenas can provide vital loci of policy debate, when these are difficult to create in policy arenas dominated by massive asymmetries of power. (b) Specialized fields of study related to the focal concern (e.g., environmental studies in our case) can also contribute tactical support and highly relevant loci of debate. In addition, they are essential because in complex policy fields, policy and scientific debates are increasingly intertwined. Getting an adequate grasp for concern-focused evaluation requires a good knowledge of, and strong connection with, the specialized field of study related to the concern. These are clearly easier and stronger if the evaluator has collaborated over time with that field of study. 
To push the limits of evaluation even further, the evaluation field ought to connect more closely with new specialized fields of application. On the environment, a necessary first step is now to combine more clearly two quite different fields of study (Billé, 2007). On one hand, the analysis and assessment of environmental policies falls clearly within the domain of policy evaluation. On the other hand, the necessity of simultaneously evaluating those policies that impact the focal concern brings us into the domain of environmental impact assessment (Fischer, 2007). The two fields currently tend to be disconnected both academically and practically. They must be reconnected. To account for environmental outcomes, evaluation of specialized environmental policies, on the one hand, is too narrow, because the outcomes are determined largely by other, nonenvironmental, policies. On the other hand, impact assessment of sector-based policies (which is the basis of environmental strategic assessment) is not focused enough, because assessing as it does the impact of one sectoral program or policy does not give an adequate grasp of outcomes on a given environmental concern, which is determined by a larger set of policies. By articulating together "actual policy" (including relevant sector-based policies) and "intentional" environmental policy, the concern-focused approach can provide a framework to mobilize both fields and link them together in a clear and relevant way.

\section{Conclusion}

To sum up, the complexity and ambiguities of current policies in the field of environment and sustainable development call for new evaluation approaches. These need to be more focused on specific concerns, more clearly strategy-driven, and in deeper connection with research and critical scholarship. This article has presented and illustrated the main foundations and steps of such an approach. In the discussion, it has also explained differences and possible connections with some other, wellestablished evaluation approaches.

We are well aware that the strategic contexts of policy evaluation are very different depending inter alia on national regimes and traditions. This has a crucial effect on the loci of pluralistic debate. It cannot be assumed that they function in the same way in Senegal, in France, in the United States, or in northern European countries. Our own focus on ambiguity and the encroachment of sectoral stakeholders on pluralistic evaluation procedures may be partly due to the specifics of the French administrative and policy context. However, these issues are not confined to France, and concern-focused evaluation may provide useful resources in other contexts with similar issues.

Finally, although our research covers only the environmental field, we would like to conclude by speculating that the current evolutions and trends in policy making that we find to be so crucial in our field (conflicting goals, deferment and transfer of decision making, intertwined scientific-technical, and political issues) may also be very important in other domains (like health, social and urban policies, research and development, etc.). Although we cannot substantiate this speculation with informed examples, we tried to present here our concern-focused, strategy-driven approach in such general terms that it may be easier for readers and evaluators to consider whether and how it may also be relevant in the policy domains in which they are involved.

\section{Note}

1. In the rest of this article, unless otherwise specified, we will use the word "policy" in its broadest meaning, that is, for all kinds of organized forms of public action, including projects, plans, programs, legislation on policy, and incentive systems, and so on.

\section{Authors' Note}

This article was written further to an invitation of the lead author as a visiting scholar to the Smith School of Enterprise and the Environment and Merton College, Oxford University. 


\section{Declaration of Conflicting Interests}

The authors declared no conflicts of interest with respect to the authorship and/or publication of this article.

\section{Funding}

The author(s) received no financial support for the research and/or authorship of this article.

\section{References}

Abma, T. A., \& Stake, R. E. (2001). Stake's responsive evaluation: Core Ideas and evolution. New Directions for Evaluation, 92, 7-21.

Arts, B., \& Leroy, P. (Eds.). (2006). Institutional dynamics in environmental governance (environment \& policy). Dordrecht, the Netherlands: Springer.

Billé, R. (2007). A dual-level framework for evaluating integrated coastal management beyond labels. Ocean \& Coastal Management, 50, 796-807.

CIME. (1994). Les Zones Humides, Rapport de l'Instance d'Evaluation. Paris, France: La documentation française.

Collectif ComMod. (2005). La modélisation comme outil d'accompagnement. Natures, Sciences, Sociétés, 13, 165-168.

Cousins, J. B., \& Earl, L. M. (1992). The case for participatory evaluation. Educational evaluation and policy analysis, 14, 397-418.

Crabbé, A., \& Leroy, P. (2008). The handbook of environmental policy evaluation. London, UK: Earthscan.

Fetterman, D., \& Wandersman, A. (2007). Empowerment evaluation: Yesterday, today and tomorrow. American Journal of Evaluation, 28, 179-198.

Fischer, T. B. (2007). The theory and practice of strategic environmental assessment. Towards a more systematic approach. London, UK: Earthscan.

Greene, J. C., \& Abma, T. A. (2001). Editors' note to the issue on responsive evaluation. New Directions for Evaluation, 92, 1-5.

Guba, E. G., \& Lincoln, Y. S. (1981). Effective evaluation: Improving the usefulness of evaluation results through responsive and naturalistic approaches. San Francisco, CA: Jossey-Bass.

Guba, E. G., \& Lincoln, Y. S. (1989). Fourth generation evaluation. Newbury Park, CA: SAGE.

Holling, C. S. (1978). Adaptive environmental assessment and management. Chichester, UK: John Wiley, IIASA.

House, E. R., \& Howe, K. R. (1998). Deliberative democratic evaluation in practice. Boulder: University of Colorado.

Knaap, G. J., \& Kim, T. J. (Eds.). (1998). Environmental evaluation, a primer. Urbana: University of Illinois Press.

Lafferty, W. M., \& Hovden, E. (2003). Environmental policy integration: Towards an analytical framework. Enviromental Politics, 12, 1-22.

Lascoumes, P., \& Setbon, M. (1996). L'évaluation pluraliste des politiques publiques-enjeux, pratiques, produits. Paris, France: G.A.P.P.-CNRS/Commissariat Général du Plan.

Lehtonen, M. (2006). Deliberative democracy, participation, and OECD peer reviews of environmental policies. American Journal of Evaluation, 27, 185-200.

Leroy, M. (2006). Gestion stratégique des écosystèmes du fleuve Sénégal: Action et inaction publiques internationales. Paris, France: L'Harmattan.

Manin, B. (1987). On legitimacy and political deliberation. Political Theory, 15, 338-368.

Mermet, L. (1996). Les études d'évaluation entre stratégie et méthodologie-l'exemple des politiques publiques en matière de zones humides. Gérer et Comprendre, 46, 55-64.

Mermet, L., \& Benhammou, F. (2005). Assurer l'inaction dans un monde familier: la fabrication stratégique de l'incertitude. Ecologie et politique, 31, 121-136. 
Mermet, L., Billé, R, Leroy, M., Narcy, J. -B., \& Poux, X. (2005). L'analyse stratégique de la gestion environnementale: un cadre théorique pour penser l'efficacité en matière d'environnement. Natures, Sciences, Sociétés, 13, 127-137.

Mermet, L., Dubien, I., Emerit, A., \& Laurans, Y. (2004). Les porteurs de projets face à leurs opposants: Six critères pour évaluer la concertation en aménagement. Politiques et Management Public, 22, 1-22.

Mickwitz, P. (2003). A framework for evaluating environmental policy instruments: Context and key concepts. Evaluation, 9, 415-436.

Miller, R. L., \& Campbell, R. (2006). Taking stock of empowerment evaluation-An empirical review. American Journal of Evaluation, 27, 296-319.

Mintzberg, H. (1978). The structuring of organizations. Upper Saddle River, NJ: Prentice Hall.

Mitsch, W. J., \& Gosselink, J. G. (2007). Wetlands. Hoboken, NJ: Wiley.

Monnier, E. (1992). Evaluation de l'action des pouvoirs publics. Paris, France: Economica.

Patton, M. Q. (1986). Utilization-focused evaluation. Newbury Park, CA: SAGE.

Patton, M. Q. (1997). Toward distinguishing empowerment evaluation and placing it in a larger context. Evaluation Practice, 18, 147-163.

Pawson, R., \& Tilley, N. (1997). Realistic evaluation. London, UK: SAGE.

Stame, N. (2004). Theory-based evaluation and types of complexity. Evaluation, 10, 58-76.

Stufflebeam, D. L. (2001). Evaluation models. New Directions for Evaluation, 89, 7-99.

Themessl-Huber, M. T., \& Grutsch, M. A. (2003). The shifting locus of control in participatory evaluations. Evaluation, 9, 92-111.

United Nations Development Programme. (1997). Who are the question-makers? A participatory evaluation handbook. New York, NY: UNDP Office of Evaluation and Strategic Planning.

Uusikylä, P., \& Valovirta, V. (2004). Three spheres of performance governance. Spanning the boundaries from single-organisation focus towards a partnership network. Paper presented at the European Group of Public Administration Annual Conference, Ljubljana, Slovenia.

van den Belt, M. (2004). Mediated modelling: A systems dynamic approach to environmental consensus building. Washington, DC: Island Press.

Vedung, E. (1997). Public policy and program evaluation. London, UK: Transaction Publishers.

Viveret, P. (1989). L'évaluation des politiques et des actions publiques-Propositions en vue de l'évaluation du revenu minimum d'insertion (Collection des rapports officiels). Paris, France: Rapports au Premier Ministre.

World Commission on Dams. (2000). Dams and development-A new framework for decision-making. London, UK: Earthscan Publications. 